\title{
Influence of stratospheric circulation on the predictability of the tropospheric Northern Annular Mode
}

\section{$\operatorname{AUTHOR(S):~}$}

Mukougawa, Hitoshi; Hirooka, Toshihiko; Kuroda, Yuhji

\section{CITATION:}

Mukougawa, Hitoshi ...[et al]. Influence of stratospheric circulation on the predictability of the tropospheric Northern Annular Mode. Geophysical Research Letters 2009, 36(8): L08814.

\section{ISSUE DATE:}

2009-04

URL:

http://hdl.handle.net/2433/84861

\section{RIGHT:}

An edited version of this paper was published by AGU. Copyright (2009) American Geophysical Union.; This is not the published version. Please cite only the published version.; この論文は出版社版でありません。引用の際には出版社版をご確認ご利用くだ さい。 


\section{Influence of Stratospheric Circulation on the Predictability of the Tropospheric Northern Annular Mode}

Hitoshi Mukougawa

${ }_{4}$ Disaster Prevention Research Institute, Kyoto University, Uji, Japan

Toshihiko Hirooka

${ }_{5}$ Department of Earth and Planetary Sciences, Kyushu University, Fukuoka,

6 Japan

Yuhji Kuroda

7 Meteorological Research Institute, Tsukuba, Japan

H. Mukougawa, Disaster Prevention Research Institute, Kyoto University, Uji 611-0011, Japan. (mukou@dpac.dpri.kyoto-u.ac.jp)

T. Hirooka, Department of Earth and Planetary Sciences, Kyushu University, Fukuoka 8128581, Japan. (hirook@geo.kyushu-u.ac.jp)

Y. Kuroda, Meteorological Research Institute, Tsukuba 305-0052, Japan. (kuroda@mrijma.go.jp)

D R A F T

March 31, 2009, 8:48pm

D R A F T 
X - 2 MUKOUGAWA ET AL: STRATOSPHERIC INFLUENCE ON NAM FORECAST

8 Influence of stratospheric circulation on the predictability of the tropospheric

9 Northern Hemisphere Annular Mode (NAM) in the boreal winter is exam-

${ }_{10}$ ined using 5-year archive of 1-month ensemble forecast dataset provided by

11 the Japan Meteorological Agency (JMA). It is found that the prediction skill

${ }_{12}$ of the 7-day averaged ensemble-mean NAM index in the upper troposphere

${ }_{13}$ is significantly improved for 5- to 13-day forecast when negatively large NAM

${ }_{14}$ indices are observed in the stratosphere around $30 \mathrm{hPa}$ at the initial time

15 of forecast in comparison with stratospheric positive NAM events. The re-

${ }_{16}$ gression analysis also supports the significant relationship between large pre-

${ }_{17}$ diction error of the upper tropospheric NAM index and stratospheric west-

${ }_{18}$ erly anomalies. The asymmetric response of the forecast skill of the upper

19 tropospheric NAM index to the polarity of the stratospheric NAM anomaly

20 is also discussed in terms of the dependence of the upward propagation of

${ }_{21}$ planetary waves on stratospheric zonal wind anomalies. 


\section{Introduction}

${ }_{22}$ It is important to reveal the influence of the stratospheric circulation change on the

${ }_{23}$ predictability of the troposphere so as to improve the forecast skill of the extended-range

${ }_{24}$ prediction as well as the understanding of the stratosphere-troposphere dynamical cou-

${ }_{25}$ pling. The Northern Annular Mode (NAM) corresponding to the dominant hemispheric

${ }_{26}$ zonally-symmetric variability is a key to understand the stratospheric influence due to

${ }_{27}$ its downward migration properties [Baldwin and Dunkerton, 1999, 2001]. Baldwin et al.

${ }_{28}$ [2003] showed significant improvement of forecast skill of a statistical prediction for the

${ }_{29}$ surface NAM variability in mid-winter when the lowermost stratospheric NAM is used as

so the predictor instead of the surface NAM variability.

${ }_{31}$ Recently, by conducting forecast experiments in the framework of the perfect model

32 assumption [Kalnay, 2003], Kuroda [2008] showed a prolonged predictable period of tro-

3з pospheric NAM variability up to 2 months for 2003/04 winter when large stratospheric

${ }_{34}$ NAM variability was observed. He also indicated that the predictable period was much

${ }_{35}$ limited (3 weeks) for 2002/03 winter when the NAM variation was weak. Although his

${ }_{36}$ study suggests the possible influence of the stratospheric variation on the predictability of

${ }_{37}$ the weather forecast, the perfect model experiment tends to overestimate the predictable

${ }_{38}$ period. In fact, the predictable period of the tropospheric NAM variability assessed by

39 the operational 1-month ensemble forecasts of the Japan Meteorological Agency (JMA)

${ }_{40}$ is at most 6 days for 2002/03 winter [Mukougawa and Hirooka, 2007; hereafter referred to

${ }_{41}$ as $\mathrm{MH07]}$. 
$\mathrm{X}-4$

MUKOUGAWA ET AL.: STRATOSPHERIC INFLUENCE ON NAM FORECAST

${ }_{42}$ Hence, in this study, we will examine the dependence of the practical predictability of

${ }_{43}$ the tropospheric NAM variability on the stratospheric NAM anomaly. For this purpose,

${ }_{44}$ we analyze the 1-month (34-day) forecast data set of the JMA for 5 winter seasons from

${ }_{45} 2001 / 02$ to $2005 / 06$.

\section{Data and Analysis Method}

${ }_{46}$ During the analysis period, the JMA 1-month ensemble predictions were carried out ${ }_{47}$ twice a week starting from 12 UTC every Wednesday and Thursday. Each ensemble ${ }_{48}$ prediction has 13 initial conditions. Here, the winter season is defined by a 4-month 49 period from December to March, and we analyze forecasts starting from November 30 to

${ }_{50}$ February 28 (13 weeks for each winter). Hence, there are 26 ensemble forecasts in each ${ }_{51}$ winter. The 1-month predictions during this period were performed using a JMA global ${ }_{52}$ spectral model (JMA-GCM0103) with triangular 106 truncation (T106) and 40 vertical ${ }_{53}$ levels up to $0.4 \mathrm{hPa}$. For further model details, the reader should refer to MH07. The ${ }_{54}$ forecast data has been archived every $24 \mathrm{hr}$ on a $2.5^{\circ} \times 2.5^{\circ}$ longitude-latitude grid at 22 ${ }_{55}$ levels from 1000 to $1 \mathrm{hPa}$. To verify the forecasts, JMA Global Analyses (GANAL) data 56 set with 1.25-degree horizontal resolution at 23 levels from 1000 to $0.4 \mathrm{hPa}$ is used.

${ }_{57}$ We also used ERA-40 data set from November 1, 1957 to April 30, 2002 with 2.5-degree

${ }_{58}$ horizontal resolution at 23 pressure levels from 1000 to $1 \mathrm{hPa}$ to define the NAM pattern ${ }_{59}$ by the following procedure as in MH07. First, we performed an EOF analysis to the ${ }_{60}$ monthly-mean height anomalies from November to April north of $20^{\circ} \mathrm{N}$ at each pressure ${ }_{61}$ level. Second, the regressed height anomaly to the corresponding 1st principal component ${ }_{62}$ is defined as the NAM pattern. Finally, the daily NAM index is obtained by projecting 
${ }_{63}$ height anomaly on to the NAM pattern. Here, the anomaly is defined as a departure from

${ }_{64}$ daily climatology created by 60-day low-pass filtered daily-mean values at each calendar

${ }_{65}$ day. The positive (negative) NAM indices represent westerly (easterly) anomalies around

${ }_{66} 60^{\circ} \mathrm{N}$.

To focus on the low-frequency variations of the NAM index, we will examine 7-dayrunning averaged ensemble-mean fields of the forecast in the following analysis. To construct 7-day running mean at day 0-3 prediction, GANAL data from day -3 to day -1 was used. The forecast skill is assessed using mean square error (MSE) and mean square spread (MSS) of the forecast at lead time $t$ defined by

$$
\begin{gathered}
\mathrm{MSE} \equiv \frac{1}{N} \sum_{i=1}^{N}\left(\overline{e_{i}(t)}\right)^{2}, \\
\mathrm{MSS} \equiv \frac{1}{N M} \sum_{i=1}^{N} \sum_{j=1}^{M}\left(e(t)_{i}^{j}-\overline{e_{i}(t)}\right)^{2},
\end{gathered}
$$

${ }_{67}$ respectively. Here, $e(t)_{i}^{j}$ is the forecast error of member $j$ for the $i-t h$ ensemble forecast,

${ }_{68} \overline{e_{i}(t)}$ the ensemble-mean forecast error, $M(=13)$ the number of member for each ensemble

${ }_{69}$ prediction, and $N$ the number of the ensemble predictions $(N=2 \times 13 \times 5=130$ for 70 all ensemble predictions of the 5 winters from 2001/02 to 2005/06). Hereafter, MSE and ${ }_{71}$ MSS at each pressure level are normalized by the climatological variance of the NAM 72 index for the 5 winters.

\section{Results}

\subsection{Comparison between 2003/04 and 2004/05 Winter}

At first, we will compare seasonal mean of the forecast error of the NAM index for the ${ }_{74}$ 2003/04 winter with the 2004/05 winter. As seen in Figures 1a, the 2003/04 winter is ${ }_{75}$ characterized by the prevailing downward migration of negative NAM anomalies from the 
$\mathrm{X}-6$

${ }_{76}$ upper stratosphere down to the surface. A major stratospheric sudden warming (SSW)

77 took place in January 2004. On the other hand, the stratospheric circulation in the

${ }_{78}$ 2004/05 winter is characterized by positive NAM anomalies. Seasonally averaged [i.e.,

79 $N=26$ in Eq.(1)] MSEs of the NAM index at each pressure level against the lead time

so are shown in Figures $1 \mathrm{~b}$ and $1 \mathrm{~d}$. These two figures show that the prediction skill of the

${ }_{81}$ NAM index in the troposphere and stratosphere for the 2003/04 winter is better than the

${ }_{82} 2004 / 05$ winter for the forecast period up to 30 days. For example, the 500-hPa MSE

8з exceeds 0.5 (half the climatological variance of NAM index) for the forecast beyond 9-day

${ }_{84}$ lead time for the 2004/05 winter whereas it is smaller than 0.5 until 12-day forecast for

${ }_{85}$ the $2003 / 04$ winter.

${ }_{86}$ Thus, these results might suggest that the prediction error for the tropospheric NAM

${ }_{87}$ index becomes smaller when the negative NAM anomalies are observed in the stratosphere

${ }_{88}$ at the initial time of forecast. In the following, we will statistically examine the relevance

${ }_{89}$ of this suggestion using the 5 winter archive of the JMA 1-month forecast.

\subsection{Classification by Stratospheric NAM}

90 Firstly, we investigate the statistical significance of the difference in MSE and MSS

${ }_{91}$ between two groups with positively or negatively large initial NAM anomalies in the

${ }_{92}$ stratosphere. Figure 2a shows an example of dependence of MSE of the 250-hPa NAM

93 index on the initial 30-hPa NAM index. The blue and red solid lines show MSEs of the

${ }_{94}$ forecasts for which initial 30-hPa NAM index is larger than 1 (climatological variance) and

${ }_{95}$ smaller than -1, respectively. Hereafter, the former (latter) is called as positive (negative)

${ }_{96}$ group. The number of the forecasts belonging to the positive and negative groups is 20 
${ }_{97}$ and 48, respectively. The black line is the averaged MSE for the other forecasts (normal ${ }_{98}$ group) of which number is 62 . The statistical significance for the difference in MSE 99 and MSS between the positive and negative groups at the lead time $t$ in the following 100 analysis is estimated by a procedure as in Shiogama and Mukougawa [2005] with 10000 101 resampled data. Figure 2a shows that the difference of MSE between the two groups is statistically significant at the $99 \%$ confidence level for the lead time between 5 and 13 ${ }_{103}$ days. In particular, the significance becomes higher than $99.9 \%$ for the lead time between ${ }_{104} 6$ and 10 days. It should be also remarked that MSE of the normal group (black line) 105 just lies between positive and negative ones for the lead times between 5 and 13 days, which implies almost linear relationship between MSE and 30-hPa NAM index. The broken lines in Figure 2a indicate squared magnitude of the mean error of the ensemble108 mean prediction, $\left(\sum \overline{e_{i}(t)} / N\right)^{2}$, corresponding to the systematic error for each group. The 109 systematic errors are much smaller than the MSEs, which indicates that the difference in ${ }_{110}$ MSE is not due to the model bias.

Figure $2 \mathrm{~b}$ shows that the 30 -hPa NAM anomaly also significantly affects MSE in the ${ }_{112}$ lower stratosphere and upper troposphere for the lead time around 8 days, and the longest ${ }_{113}$ interval of the lead time with significant difference around 8-day forecast is observed for the 250-hPa NAM prediction. However, the stratospheric NAM anomalies do not affect 115 the predictability of the lower tropospheric NAM during this forecast period. We will ${ }_{116}$ focus on the forecast of the 250-hPa NAM index for the lead time around 8 days in the ${ }_{117}$ following analysis. 
Secondly, we examine the pressure level of which NAM index most significantly affects the forecast skill of the 250-hPa NAM prediction. Figure 2c shows differences in MSE

${ }_{120}$ of the $250-\mathrm{hPa}$ NAM index between the positive $(\mathrm{NAM} \geq 1)$ and negative $(\mathrm{NAM} \leq-1)$

${ }_{121}$ groups classified by the initial NAM index at each pressure level (the ordinate). For ${ }_{122}$ example, this figure shows that MSE of the 250-hPa NAM index for the negative group is significantly smaller than that for the positive group when the forecasts are classified by ${ }_{124}$ NAM anomalies above $200 \mathrm{hPa}$. In particular, the 30-hPa NAM index most significantly 125 affects the 8-day forecast skill of the 250-hPa NAM index since the difference attains the highest statistical significance (99.997\%). Figure 2c also shows that stratospheric ${ }_{127}$ NAM variations at upper pressure levels tend to influence the forecast skill of the 250-hPa ${ }_{128}$ NAM index for longer lead times. For example, the 5-hPa NAM variations produce the ${ }_{129}$ largest difference in MSE of the 250-hPa NAM index around 18-day forecast. It is also ${ }_{130}$ interesting to note that when mid-tropospheric NAM index has positively large values, the predictability of the 250-hPa NAM index for 10-23 day lead time tends to be enhanced.

Figure 3 shows the time evolution of mean square spread (MSS), defined by Eq.(2),

${ }_{133}$ of the 250 -hPa NAM index for the positive and negative groups classified by the $30-\mathrm{hPa}$

${ }_{134}$ NAM index as in Figure 2a. The negative group has significantly smaller MSS than the positive group at $99.9 \%$ confidence from 5-day to 19-day forecast. Hence, it is suggested among the positive group (blue broken line) is larger than that for the negative group (red 
${ }_{140}$ broken line) after 2 days from the initial time in accordance with the significant difference

${ }_{141}$ in MSS between the two groups.

\subsection{Regression Analysis of Tropospheric NAM Error}

We also made a regression analysis with respect to MSE of the 250-hPa NAM index ${ }_{143}$ using all ensemble predictions $[N=130$ in Eq.(1)]. Figure 4 shows regressed zonal144 mean zonal wind and E-P flux of zonal wavenumber 1 (WN1) at the initial time of 145 forecast. The statistical significance is assessed by the Student's $t$-test. Figure 4a indicates that larger MSE of 250-hPa NAM index for 12-day prediction is related to westerly anomalies in the upper stratosphere in mid-latitudes. For 8-day NAM prediction, the related westerly anomalies extend downward to the lower stratosphere around $50^{\circ} \mathrm{N}$ correlated stratospheric westerly anomaly and its downward extension are also confirmed 151 from Figure 2.

Figure 4 also gives us an plausible explanation for the downward extension of the cor${ }_{153}$ related westerly anomaly. The regressed WN1 E-P flux vectors indicate that larger MSE ${ }_{154}$ of the $250-\mathrm{hPa}$ NAM index is associated with downward and equatorward propagation ${ }_{155}$ of anomalous WN1 wave activity in the lower stratosphere and upper troposphere. The ${ }_{156}$ WN2 component also has less significant E-P flux anomalies in the stratosphere (not shown). The accompanied anomalous E-P flux divergence of both components in the ${ }_{158}$ lower stratosphere (not shown) will extend the westerly anomaly downward. 


\section{Concluding Remarks}

In order to examine the influence of the stratospheric circulation on the predictability 
${ }_{180}$ of WN1 component. This might be related to the important role of WN1 component for

181 the downward shift of the regressed stratospheric westerly anomalies.

${ }_{182}$ Our results are also consistent with Kuroda [2008] which remarked very high predictabil-

${ }_{183}$ ity of the tropospheric circulation just before the occurrence of a major SSW, correspond-

${ }_{184}$ ing to a negatively large NAM event. He argued the high predictability in connection with the magnitude of stratospheric circulation anomalies. However, our study insists

Acknowledgments. We thank two anonymous reviewers for constructive comments.

The JMA data used in this study was provided by way of "Meteorological Research Consortium", a framework for research cooperation of JMA and MSJ. This work was supported by a Grant-in-Aid for Scientific Research (A) and (B) from JSPS. The GFDDENNOU Library was used for the graphics.

\section{References}

Baldwin, M. P., and T. J. Dunkerton (1999), Propagation of the Arctic Oscillation from the stratosphere to the troposphere. J. Geophys. Res., 104, 30937-30946. weather regimes. Science, 294, 581-584. 
$\mathrm{X}-12$ MUKOUGAWA ET AL.: STRATOSPHERIC INFLUENCE ON NAM FORECAST

${ }_{200}$ Baldwin, M. P., D. B. Stephenson, D. W. J. Thompson, T. J. Dunkerton, A. J. Charlton, and A. O’Neil (2003), Stratospheric memory and skill of extended-range weather forecasts. Science, 301, 636-640.

203 Cambridge Univ. Press, doi:10.2151/sola.2005-033. 
Figure 1. (a) Time variation of observed NAM index at each pressure level for 2003/04 winter. (b) MSE of the NAM index at each pressure level for 2003/04 winter. The absicca is the lead time in days. The values less than 0.5 (1.0) are heavily (lightly) shaded. The right panels are the same as the left ones except for 2004/05 winter.

Figure 2. (a) Time evolution of MSE of the NAM index for the forecasts classified by the initial 30-hPa NAM index against the lead time (solid lines). Broken lines are the squared magnitude of the mean error of the ensemble-mean forecast. Blue (red) lines are for the positive (negative) group. Time intervals of the lead time when the difference in MSE of the NAM index between the two groups is significant at 99.9 (99)\% confidence are heavily (lightly) shaded. The black line shows MSE for the normal group. (b) Difference in MSE at each pressure level between the two groups classified by the initial 30-hPa NAM. (c) Difference in MSE of the 250-hPa NAM index between the two groups classified by initial NAM index at each pressure level (the ordinate). Positive values in (b) and (c) indicate larger MSE for the positive group. The absicca is the lead time in days, and statistically significant regions are shaded as in (a).

Figure 3. As in Figure 2a except for MSS of the NAM index. Time intervals when the difference in MSS between the two groups is significant at 99.9 (99)\% confidence are heavily (lightly) shaded. Broken lines show the variance of 7-day averaged observed NAM index from the initial time for each group. Blue (red) lines are for the positive (negative) group. 
Figure 4. Regressed anomalies of zonal-mean zonal wind (contours: $\mathrm{m} \mathrm{s}^{-1}$ ) at the initial time of forecast on MSE of the 250-hPa NAM index for (a) 12-day, (b) 8-day, and (c) 4-day forecasts. Regions are heavily (lightly) shaded where correlation coefficients are significant at 99 (95)\% confidence. The vectors indicate the regressed WN1 E-P flux anomalies $\left(\mathrm{Kg} \mathrm{s}^{-2}\right)$ of which vertical or horizontal components are significant at the $90 \%$ level, and the magnitude of the vector is scaled by the reciprocal square root of the pressure. 


\section{3/04}

(a) Observed NAM

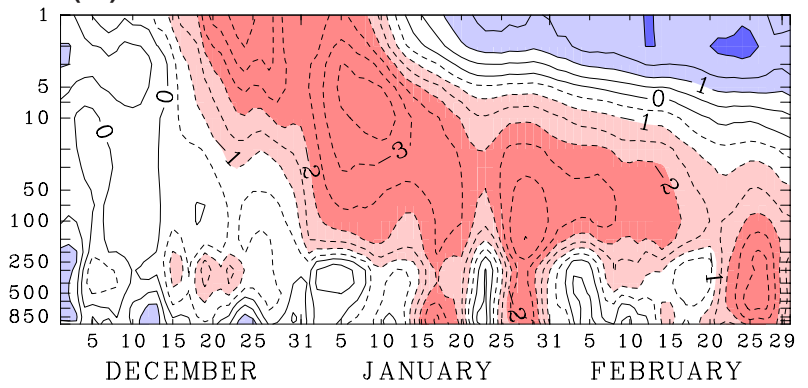

(b) MSE of NAM

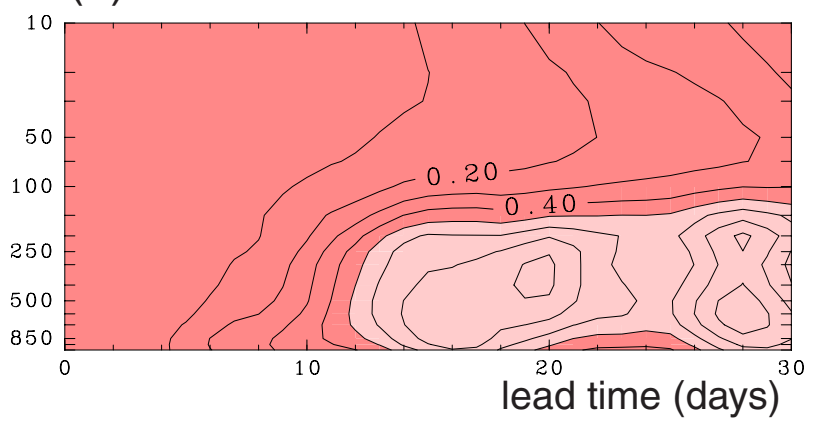

2004/05

(c) Observed NAM

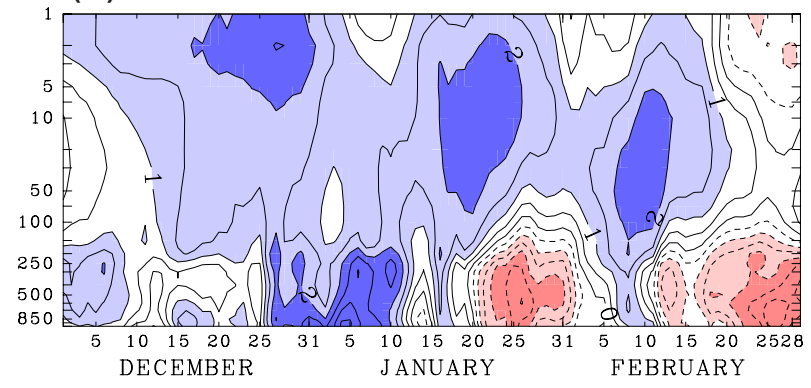

(d) MSE of NAM

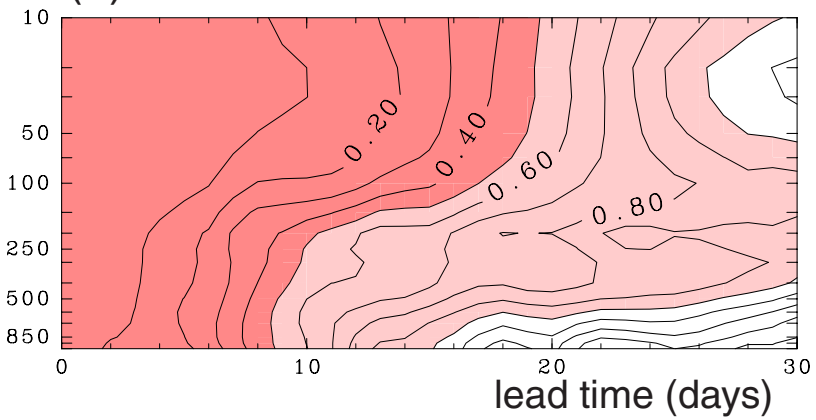


(a) $250 \mathrm{hPa}$ MSE of NAM

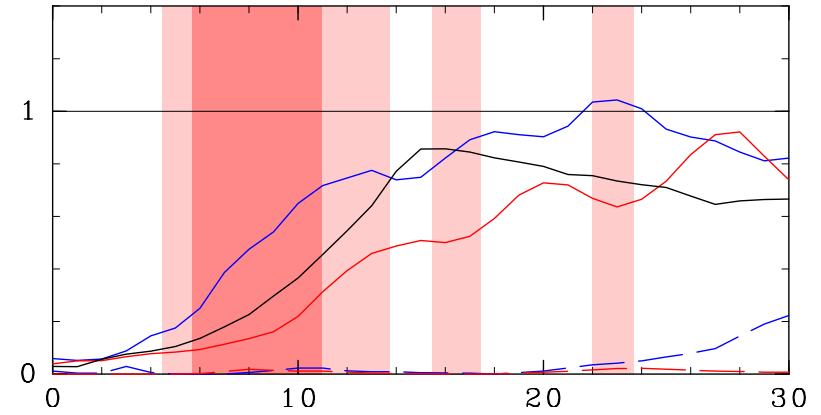

(b) MSE Diff. of NAM (P-N)

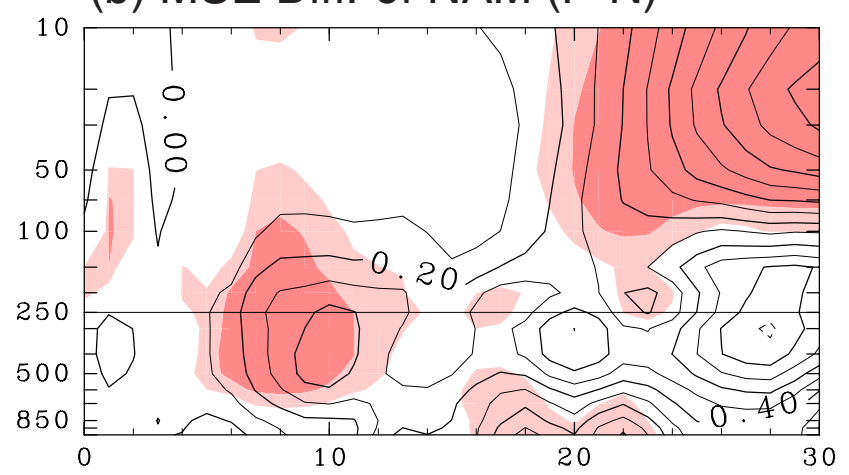

(c) MSE of $250 \mathrm{hPa}$ NAM

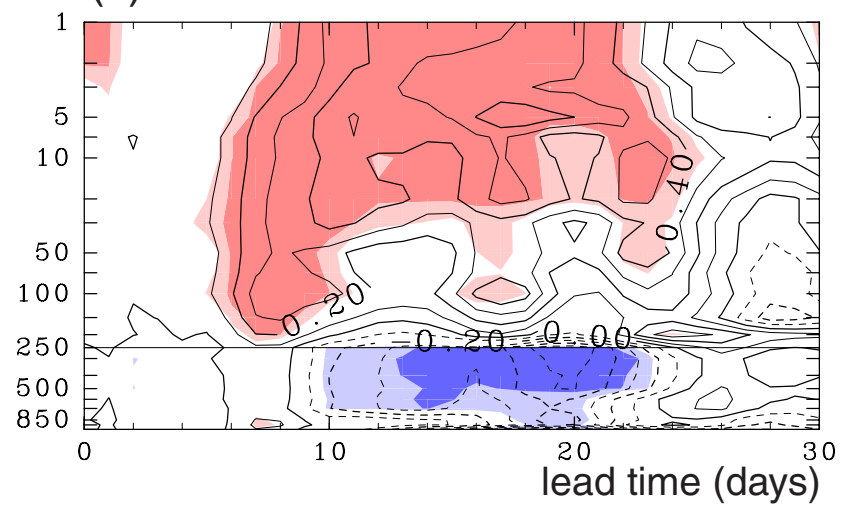




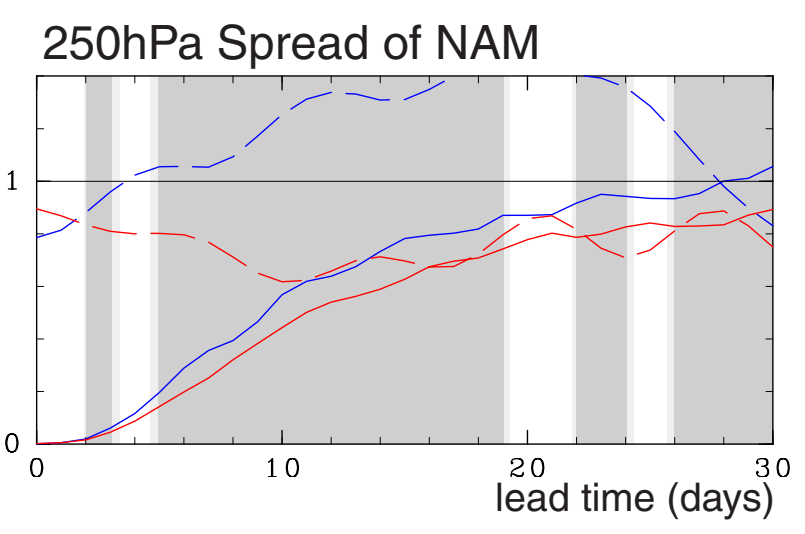


(a) Day 12

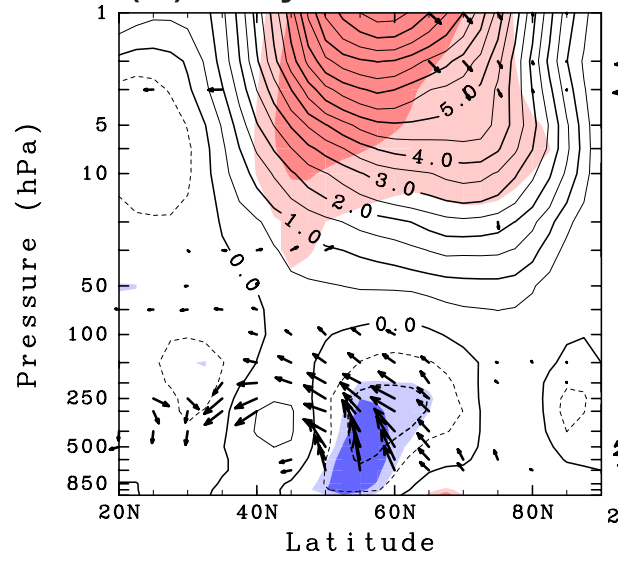

(b) Day 8

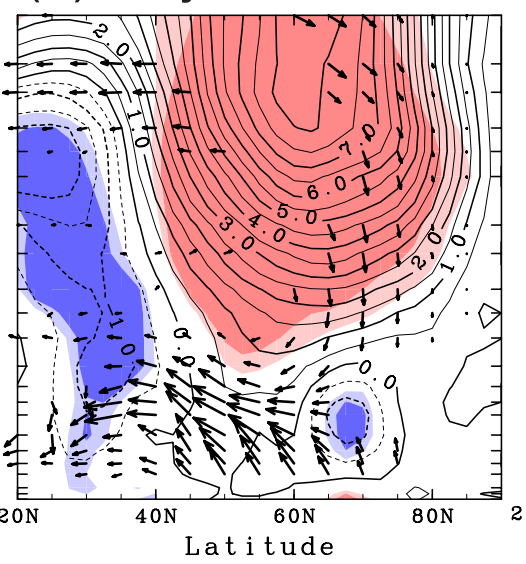

(c) Day 4

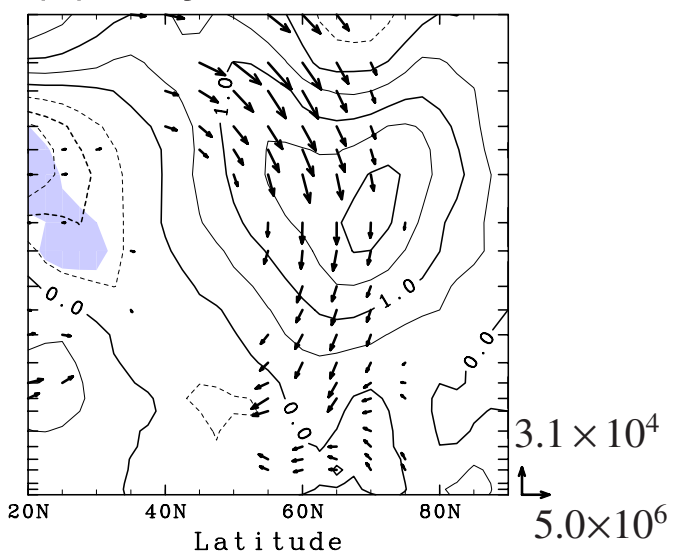

